\title{
Everyday happiness: Gifting and eating as everyday activities that influence general positive affect and discrete positive emotions
}

\author{
Robert Hurling $\cdot$ Alex Linley $\cdot$ Helen Dovey $\cdot$ John Maltby $\cdot$ Joy Wilkinson
}

\begin{abstract}
Positive psychology interventions have tended to be intentional cognitive and / or behavioural activities, specifically designed by researchers to increase happiness and wellbeing. In everyday life, however, people naturally undertake activities to increase their happiness and wellbeing. In this study, we examine and compare gifting and eating as two types of everyday activity that influence Positive Affect and so also happiness and wellbeing. Two hundred participants were allocated to four groups to examine the impact of gifting and eating, both individually and combined, relative to a control group, on happiness and wellbeing. Results show that giving a desirable food (ice cream) to another person as a gift increases Positive Affect but not discrete positive emotions, whereas both eating and giving an ice cream as a gift increase both Positive Affect and discrete positive emotions. The discussion focuses on the role of everyday activities in enhancing Positive Affect with the accumulative potential to increase everyday happiness.
\end{abstract}

Keywords: Gifting, eating, positive affect, positive emotion

\section{Introduction}

People want to be happy, and a major focus of positive psychology research in the last decade has been on developing interventions that are designed to help people become happier. As a result, the happiness debate has moved on from the view that happiness is fleeting and ephemeral, and in any event, subject to the hedonic treadmill (Brickman \& Campbell, 1971, but see also Diener, Lucas, \& Scollon, 2006). Now, the evidence is starting to build that happiness can be increased sustainably (e.g., Sheldon \& Lyubomirsky, 2006), and at the same time we are understanding more about what kinds of positive psychology interventions work for different people and in different circumstances (Layous \& Lyubomirsky, in press).

The positive psychology literature continues to show the focus of researchers on developing simple activities designed to increase individual happiness and wellbeing. There is now a substantial research base empirically demonstrating the wellbeing benefits to be derived from completing intentional cognitive and behavioural activities that include, amongst others, counting one's blessings (Emmons \& McCullough, 2003), undertaking a loving-kindness meditation (Cohn \& Fredrickson, 2010), and performing acts of kindness (Layous, Nelson, Oberle, Schonert-Reichl, \& Lyubomirsky, 2012).

In a meta-analysis of positive psychology interventions, Sin and Lyubomirsky (2009) found a significant correlation with wellbeing (mean $r=.29$ ) and also an alleviation of depression (mean $r=.31$ ). As such, there is correlational evidence that positive psychology interventions work. 
It is interesting to note that across each of these studies the activities investigated have typically been developed by researchers as potential mechanisms for increasing happiness and wellbeing, and then tested as such. This is a laudable goal that is very much in keeping with the espoused aims of positive psychology, one of which is to increase human happiness (Seligman \& Csikszentmihalyi, 2000).

Stepping back, however, to take a broader perspective, one can also see that human beings have been focused on doing things to increase their happiness for a long time, and have their own naturalistic understanding of what it takes to do so (McMahan \& Estes, 2011), notwithstanding that there is also evidence of the problems that humans have with affective forecasting and predicting what is likely to make them happy (e.g., Wilson \& Gilbert, 2005).

In one of the few studies to date to take a naturalistic approach to enhancing happiness, Parks, Della Porta, Pierce, Zilca, and Lyubomirsky (2012) found that, on average, people performed their happiness activities several times a week for at least an hour each time. Clearly, then, happiness is a concept which people are minded to pursue, whether intentionally, following the positive psychology interventions developed by researchers with the specific intention of increasing happiness, or more naturalistically, through everyday activities that people believe, either generally or idiosyncratically, will increase their happiness.

As such, the focus of our current research was to explore the impact of what might be termed everyday activities on happiness. By everyday activities, we mean activities that are typical, naturalistic and usual for everyday life - and we use the term 'everyday' in a general, rather than specific, sense. That is, we use everyday to refer to something that is a normal, natural and typical exemplar, rather than something that happens with the frequency of occurring on every single day of every week.

Furthermore, we focus on the contribution of positive emotions to wellbeing, inspired by Fredrickson and Levenson's (1998) seminal broaden-and-build theory of positive emotions as well as the Lyubomirsky and Layous (2013) positive-activity model. The broaden-and-build theory suggests that positive emotions broaden awareness and encourage novel, varied, and exploratory thoughts and actions. Over time, this broadened behavioural repertoire builds skills and resources. The positive-activity model further proposes that features of positive activities (e.g. dose and variety), of the person (e.g. motivation and effort) and the person-activity fit influence the effect of positive activities on wellbeing. The role of positive emotions is now being recognized in a range of areas, e.g. resilience (Fredrickson, Tugade, Waugh, \& Larkin, 2003), reducing own-face bias in cross-race facial recognition (Johnson \& Fredrickson, 2005) and helping to build sustainable positive resources in relationships (e.g., Fredrickson, Cohn, Coffey, Pek, \& Finkel, 2008; Waugh \& Fredrickson, 2006). Boosting the frequency of experienced positive emotion in everyday life therefore appears a worthwhile enterprise to improve wellbeing (Henderson \& Knight, 2012).

Whilst there are many interrelated constructs in the happiness literature, here we refer to Positive Affect as a momentary feeling of positivity (measured by summing a range of positive emotions captured by PANAS); discrete positive emotions as single measures of a specific but still temporary emotional experience; emotional intensity as a measure of the experience strength, mood as an enduring feeling and subjective wellbeing as a combination of affect (positive and negative) combined with an evaluation of Satisfaction with Life (Linley, Maltby, Wood, Osbourne, \& Hurling, 2009). In our study we focus on the short-term and momentary development of Positive Affect, as well as discrete positive emotions, on the basis that, in line with endowment and broaden and build theories (Cheng, 2004; Fredrickson et al., 2003), these accumulate over time with a protective effect on a person's wellbeing. 
We chose to focus on the impact of eating a desirable food and/or gifting a desirable food to another person, as two prototypical activities that may be legitimately considered to increase Positive Affect (Linley et al., 2013). We do not consider that these activities will necessarily be significantly more effective at increasing Positive Affect than other categories of activity, but nonetheless, they may be considered as prototypical exemplars of everyday behaviour more than typical positive psychology interventions, as we explore next the specific rationales for our selection and inclusion of each of these activities.

\subsection{Gifting as a naturalistic source of Positive Affect}

A series of studies has demonstrated that people experience greater Positive Affect from spending money on others than from spending money on themselves (Dunn, Aknin, \& Norton, 2008). In a demonstration of what they consider may be evidence for a psychological universal, Aknin et al. (2013) showed that people around the world derive psychological benefits, including increased Positive Affect, from using their resources to help others.

Furthermore, research has shown that 'giving' in the non-material sense, such as giving one's time, help, and social support to others, leads to significant personal gains in happiness and wellbeing (Steger, Kashdan, \& Oishi, 2008) and indeed health (Post, 2005). Kogan et al. (2010) showed that making a sacrifice for one's romantic partner was associated with higher levels of positive emotion. Layous et al. (2012) showed that performing acts of kindness towards others led to increased wellbeing and also increased quality of peer relationships, while Weinstein and Ryan (2010) showed that when people volitionally help others, they experience enhanced wellbeing. Alden and Trew (2013) showed that these effects held even for socially anxious people, such that Positive Affect was increased in people with social anxiety when they undertook kind acts towards other people.

Discussing the mechanisms through which acts of kindness, which would include giving a gift to others, may increase Positive Affect, Lyubomirsky, Sheldon and Schkade (2005) identified a number of potential mechanisms. First, they suggested that acts of giving might foster a more charitable perception of others and one's community, a greater sense of connectedness and cooperation, and thus an enhanced appreciation of what is positive in one's life. Second, they suggested that people who engage in acts of kindness may start to consider themselves as being more altruistic, as well as feeling more confident, in control, and optimistic about their ability and capacity to help others. Third, giving things to others can also lead to greater liking by others, together with their appreciation and gratitude, and the potential that the kindness will be reciprocated. Finally, Lyubomirsky et al. noted that most fundamentally, kind behaviours might satisfy a fundamental human need for relatedness and feeling connected to others. For all these reasons, we hypothesized that the act of giving the gift of an ice cream would lead to increased Positive Affect.

\subsection{Eating desirable foods as a naturalistic source of Positive Affect}

Eating provides an everyday source of happiness for most people (Macht, Meininger \& Roth, 2005; Wrzesniewski, Rozin, \& Bennett, 2003). Indeed, in free report, people will readily identify eating as an activity that gives them pleasure (Berenbaum, 2002), and studies of wellbeing using the day reconstruction method have shown that eating is often cited as one of the more pleasurable activities people undertake (Kahneman, Krueger, Schkade, Schwarz \& Stone, 2004). The literature on taste as one of the sensory sources of pleasure (Rozin, 1999; Veldhuizen, Rudenga \& Small, 2010) also suggests happiness may be derived from the taste of specific foods. In early experimental studies of emotion induction, food was used as a method for increasing 
Positive Affect, most notably by Isen and Levin (1972), who gave individuals cookies as a means of inducing Positive Affect (although it is also possible that receiving the cookie enhanced Positive Affect, as we explore further in the Discussion).

People naturally employ everyday strategies to improve their emotions such as the consumption of specific 'mood foods' that are usually highly desirable. Ice cream is frequently used by popular media as an example of a mood food, but only a few studies have investigated scientifically the effects of ice cream on mood. For example, Linley et al. (2013) demonstrated that eating ice cream while thinking of things for which one was grateful led to increases in Positive Affect (Study 1), and subsequently that thinking of things for which one was grateful and eating ice cream, whether doing both together or separately, led to increases in Positive Affect (Study 2).

Walla, Richter, Farber, Leodolter and Bauer (2010) compared the effects of eating ice cream with those of eating yoghurt and of eating chocolate. Modulation of the startle response (a sudden involuntary movement in response to an intense and unexpected stimulus) was used as a measure of appetitive motivational state, which is defined as a behaviour that is directed toward goals that are usually associated with positive hedonic processes. Particularly in males, the amplitude of the startle response was lower after consumption of ice cream as compared to after consumption of yoghurt or chocolate, indicating that ice cream consumption enhanced the appetitive motivational state.

Another line of evidence stems from an fMRI study by Burger and Stice (2012). Ice cream consumption activated the oral somatosensory brain areas reflecting perception of taste, temperature, and texture more when compared to consumption of a tasteless solution. Eating ice cream also activated brain areas related to reward and motivation, and the magnitude of this activation was positively associated with lower habitual ice cream consumption. This indicates that ice cream is a pleasurable experience when consumed in moderation, although this may vary according to cultural perspectives on food as a source of pleasure. For example, Rozin, Fischler, Imada, Sarubin, and Wrzesniewski (1999) found that Americans tend to associate food most with health and least with pleasure, whereas the French in contrast tend to associate food least with health and most with pleasure. However, although perhaps obvious from a consumer point of view, there is no research on whether people actually consciously experience how ice cream makes them happy. Therefore we set out to investigate the effect of eating on wellbeing, and selected ice cream as an example of a desirable food, given its prevalence in popular culture as a 'mood food'.

\subsection{Combining eating a desirable food with gifting a desirable food}

Taken together, the studies outlined above, drawn together from different areas of the research literature, show that first, eating (particularly treats) is a fundamental and natural source of positive emotion for people, and, second, giving support to others, whether through acts of kindness, making sacrifices, or prosocial spending, leads to increased wellbeing of the giver. Developing this focus into the realm of everyday life, we were interested in how these two routes to Positive Affect may relate and interact.

We chose to focus specifically on the potential interaction between eating and gifting an ice cream because ice cream is specifically recognized as a desirable 'mood food' in many cultures (both individualistic and collectivist) and because it is a common experience to buy an ice cream for another person and share that ice cream experience with them (more so than most other types of food). By examining the role of eating and gifting ice cream as two potential routes to everyday Positive Affect, we sought to explore how everyday activities would fare in their facilitation and 
promotion of wellbeing, relative to the existing literature on more experimentally-developed, non-naturalistic positive psychology interventions.

\subsection{Happiness, Positive Affect or discrete positive emotions?}

Positive psychology interventions have been generically focused on increasing "happiness", however defined. "Happiness" as a construct may have been assessed directly using measures such as the Subjective Happiness Scale (Lyubomirsky \& Lepper, 1999), or indeed used as a general catch-all term for the positive outcome variables of interest. Within the Sin and Lyubomirsky (2009) meta-analysis, Positive Affect was the most consistently assessed variable, suggesting that many researchers have chosen to focus on this as their outcome measure of choice, quite possibly because it has a much longer and wider heritage as a predictor, in turn, of other valued outcomes (e.g., Lyubomirsky, King \& Diener, 2005; Pressman \& Cohen, 2005).

The focus on Positive Affect may also be because it is considered an exemplar element of a broader construct of subjective wellbeing that is often calculated by standardising Positive Affect, Negative Affect and life satisfaction, and then subtracting Negative Affect from the sum of Positive Affect and life satisfaction to create a composite subjective wellbeing variable (e.g., Sheldon \& Elliot, 1999).

Where Positive Affect has been the target variable of choice for researchers examining positive psychology interventions, it has typically been the Positive and Negative Affect Scales (PANAS, Watson, Clark \& Tellegen, 1988) which have been used. The PANAS measures 10 positive emotions and 10 negative emotions, which are summed to provide scores for Positive and Negative Affect respectively.

However, in Kuppens, Tuerlinckx, Russell, and Barrett's (2012) review they concluded there is no consistent evidence for a straightforward relationship between the valence (degree of positivity or negativity) and arousal (degree of experience intensity) of an emotion; it varies between individuals and contexts. Kuppens et al.'s central argument might simply be summarised as "not all emotions are created equal", which in turn led us to question whether simply summing 10 positive emotions, as is standard practice for the PANAS, would necessarily be the most insightful measurement approach.

There is also emerging interest in the question of whether all positive emotions are the same, or indeed, whether positive emotions may vary in their antecedents, correlates, sensitivities and effects. For example, tackling the question of divergent properties of discrete positive emotions directly, and showing that their differential effects resulted from differing social properties, rather than shared general Positive Affectivity, Strohminger, Lewis and Meyer (2011) demonstrated that mirth (feeling of gladness and merriment, especially when expressed by laughter) and elevation (feeling of warmth and expansion when observing another person behaving well), as two distinct positive emotions, led to distinct and differentiated moral judgments.

Examining the impact of the characteristics of leaders on organisational climate, Michie (2009) showed how the pride of leaders led to greater prosocial behaviour by those leaders through greater social justice and altruism, with this effect mediated by gratitude on social justice only, thereby differentiating pride and gratitude in this context. Further, Williams and De Steno (2008) differentiated pride from self-efficacy and general Positive Affect, proposing that pride served as a motivational incentive to persevere with a task despite the initial costs incurred.

As this small, but important, research stream is beginning to show, not all positive emotions are created equal. Unfortunately, this focus on more omnibus measures of wellbeing has limited the conclusions that can be drawn about the impacts of emotion and the emotional impacts of 
different interventions. For example, in a systematic review of 687 studies of the elicitation of discrete emotions, Lench, Flores and Bench (2011) had to limit their meta-analysis to the major emotion categories of happiness, sadness, anger and anxiety. They noted, "A review of potential discrete positive emotions was not possible because few studies included more than one of these emotions" (p. 838).

Hence, while we know a lot about broad emotion categories, much less is known about the role of specific and discrete emotions and how they may be impacted by positive psychology interventions or our everyday happiness activities. Even so, the evidence is starting to build that different positive emotions may function in different ways.

As such, a further focus of our study was to investigate the role of specific and discrete positive emotions more fully, while also allowing for comparison with previous literature by including a more traditional measure of Positive Affect, in the form of the PANAS scales. We included additional measures of 15 discrete positive emotions which had been developed from consideration of a wider set of positive emotional terms that are not included in the PANAS, but which are nonetheless relevant to the literature on positive emotions (e.g., Fredrickson et al., 2008). Our intent in including these additional positive emotions was to explore any potential impact on positive emotions that extend beyond those typically measured by the PANAS, as well as to explore these positive emotions at both the discrete and the combined level as appropriate.

We did not opt to explore the PANAS items at the individual level, given that the PANAS is a well-established and widely used measure of Positive Affect, and to conduct analyses at the individual item level would be to disregard the extensive reliability and validity evidence that has been established for the PANAS as a whole, and which is fundamental to its use by researchers.

To provide further comparison with our state measures of emotion, we also included measures of state vitality and life satisfaction. While life satisfaction is more of a trait than a state variable, there is also evidence to suggest that it can be improved in the short term (Pavot \& Diener, 1993), and we were interested to explore whether this was the case with the very short interventions we were testing here.

Hence, in summary, this study was designed to explore the independent and combined effects of eating and/or gifting a desirable food (ice cream), as everyday activities, on general Positive Affect as well as more specific and discrete positive emotions.

We did not make specific predictions for the differential influence of these activities on general Positive Affect or discrete positive emotions, given the early stage of research in this area. Our focus here was exploratory, and on this basis we considered the measures of discrete positive emotions both at the item level and also as a composite score, when analysis indicated that it was appropriate to do so.

In relation to gifting and eating, we developed the following hypotheses:

Hypothesis 1: Based on existing research, it was hypothesized that giving an ice cream as a gift to another person would increase general Positive Affect and the discrete positive emotions of the gift giver;

Hypothesis 2: Based on existing research, it was hypothesized that eating an ice cream would increase general Positive Affect and the discrete positive emotions of the ice cream eater;

Hypothesis 3: It was also hypothesized that eating ice cream and giving an ice cream as a gift to another person together would increase general Positive Affect and the discrete positive emotions of the gift giver. We were interested to establish if there was any additive or cumulative effect of these two activities combined. 
Our focus in this study was the emotional change in the main study participant, either eating and/or gifting an ice cream, not in the non-study person who received an ice cream as a gift.

\section{Methodology}

\subsection{Participants}

The participants were 200 undergraduate students, 116 female and 84 male, recruited via a major UK University. The mean age of participants was 19.84 years $(S D=3.18$ years, range $=16-47)$. Participants were typically from a White ethnic background (69.5\%). Participants were randomly allocated to one of four experimental conditions, which are described in detail in the procedure.

\subsection{Measures}

Positive and Negative Affect were assessed using the PANAS (Watson, Clark \& Tellegen, 1988), a 20-item measure scored in relation to the experience of 10 positive and 10 negative emotions at the present moment, using a 1 (very slightly or not at all) to 5 (extremely) scale. Internal consistency reliability for Positive Affect was $\alpha=0.85-0.93$ at Time 1 and $\alpha=0.78-0.89$ at Time 2, and for Negative Affect was $\alpha=0.88-0.91$ at Time 1 and $\alpha=0.86-0.92$ at Time 2 (range across the four experimental groups).

Positive Emotional Intensity of Discrete Emotions was assessed using 15 items relating to discrete positive emotion, which required participants to rate the intensity of those specific positive emotions as experienced at the present moment, using a 1 (very slightly or not at all) to 5 (extremely) scale. These positive emotions were: joyful, optimistic, satisfied, curious, happy, resilient, grateful, interested, content, loving, amused, awed, compassionate, hopeful, and proud. Internal consistency reliability for these 15 discrete positive emotions when combined as an omnibus measure was $\alpha=0.85-0.90$ at Time 1 and $\alpha=0.84-0.88$ at Time 2 (range across the four experimental groups), demonstrating that combining the items together as an omnibus measure of positive emotion was statistically coherent for the purposes of the study. However, as noted above, our interest and focus was also at the level of each discrete individual positive emotion.

Satisfaction with Life was assessed using the Satisfaction with Life Scale (SWLS, Diener, Emmons, Larsen, \& Griffin, 1985), a five-item measure, scored using a 1 (strongly disagree) to 7 (strongly agree) scale. Internal consistency reliability was $\alpha=0.86-0.89$ at Time 1 and $\alpha=0.87$ 0.91 at Time 2 (range across four experimental groups).

Vitality was assessed using the state-level version of the Subjective Vitality Scale (Ryan \& Frederick, 1997), a seven-item measure requiring participants to indicate how they feel right now in relation to given statements, scored using a 1 (not at all true) to 7 (very true) scale. Internal consistency reliability was $\alpha=0.92-0.93$ at Time 1 and $\alpha=0.89-0.92$ at Time 2 (range across four experimental groups).

Whilst ideally these measures would have been balanced for order of presentation this was not pragmatically possible in this study and so our results may have been influenced by order effects.

\subsection{Design}

The study design was a randomized, between-subjects 2 (eating / not eating ice cream) X 2 (gifting / no gifting) design. This led to four intervention groups; Gifting only (participants gifted an ice cream to another person who was not participating in the study, but did not consume an ice cream themselves), Eating only (participants consumed an ice cream only, and did not gift an ice cream to another person), Eating and Gifting (participants consumed an ice cream as well as 
gifting an ice cream to another person (typically a friend) who was not participating in the study) and Control (a neutral writing activity, where participants did not either eat or gift an ice cream). All groups completed the study measures (Time 1) before completing their given intervention within two hours on the same day. Immediately after the intervention, all groups completed the same study measures for a second time on the same day (Time 2).

\subsection{Procedure}

First, all participants completed the Positive Emotional Intensity items, Subjective Vitality Scale, PANAS, and the SWLS (Time 1). The measures were presented in this specific order, so as to assess first the emotion measures, which were state-specific.

Second, all participants completed the intervention as relevant for their group as indicated below:

Gifting only: Participants gave an ice cream as a gift to another person, who was not participating in the study, and stayed with the other person while that person ate the ice cream. The participant did not themselves eat an ice cream.

Eating only: Participants ate an ice cream by themselves. They did not have any specified interaction with other people while eating this ice cream.

Eating and Gifting: Participants gave an ice cream as a gift, and ate an ice cream themselves. They stayed with the other person while both of them ate their ice creams, i.e. they ate the ice creams together.

Control: Participants wrote 100 words describing the layout of their bedroom as a neutral writing activity (adapted from Watkins, Woodward, Stone, \& Kolts, 2003). Watkins et al. asked participants to write about their living room, but for the current study, this was adapted to bedroom, as not all participants (students potentially living in student campus accommodation) would have had their own living room.

Third and finally, all participants completed the Positive Emotional Intensity items, Subjective Vitality Scale, PANAS, and the SWLS (Time 2). Again, the measures were presented in this specific order, so as to assess first the emotion measures, which were state-specific. The intervention was completed in one sitting and participants were paid $£ 20$ in return for their participation.

\section{Data analyses}

Descriptive statistics, including Cronbach's alphas of all the study measures for the two time points were calculated. Inter-correlations between all study measures for the two time points are shown in Table 1 below.

In order to ascertain whether the random assignment of participants to intervention groups was successful, such that all groups start out equal on the study measures, the baseline data were analyzed using multivariate analyses of variance (MANOVA).

In order to examine the impact of gifting and eating on happiness and wellbeing (hypotheses 1-3), the data were analyzed using two-way Analyses of Covariance (ANCOVA). The use of ANCOVA models allowed comparisons across time points following the intervention, while controlling for pre-intervention levels of the variable. 
Table 1: Inter-correlations between study measures $(\mathbf{N}=\mathbf{2 0 0})$

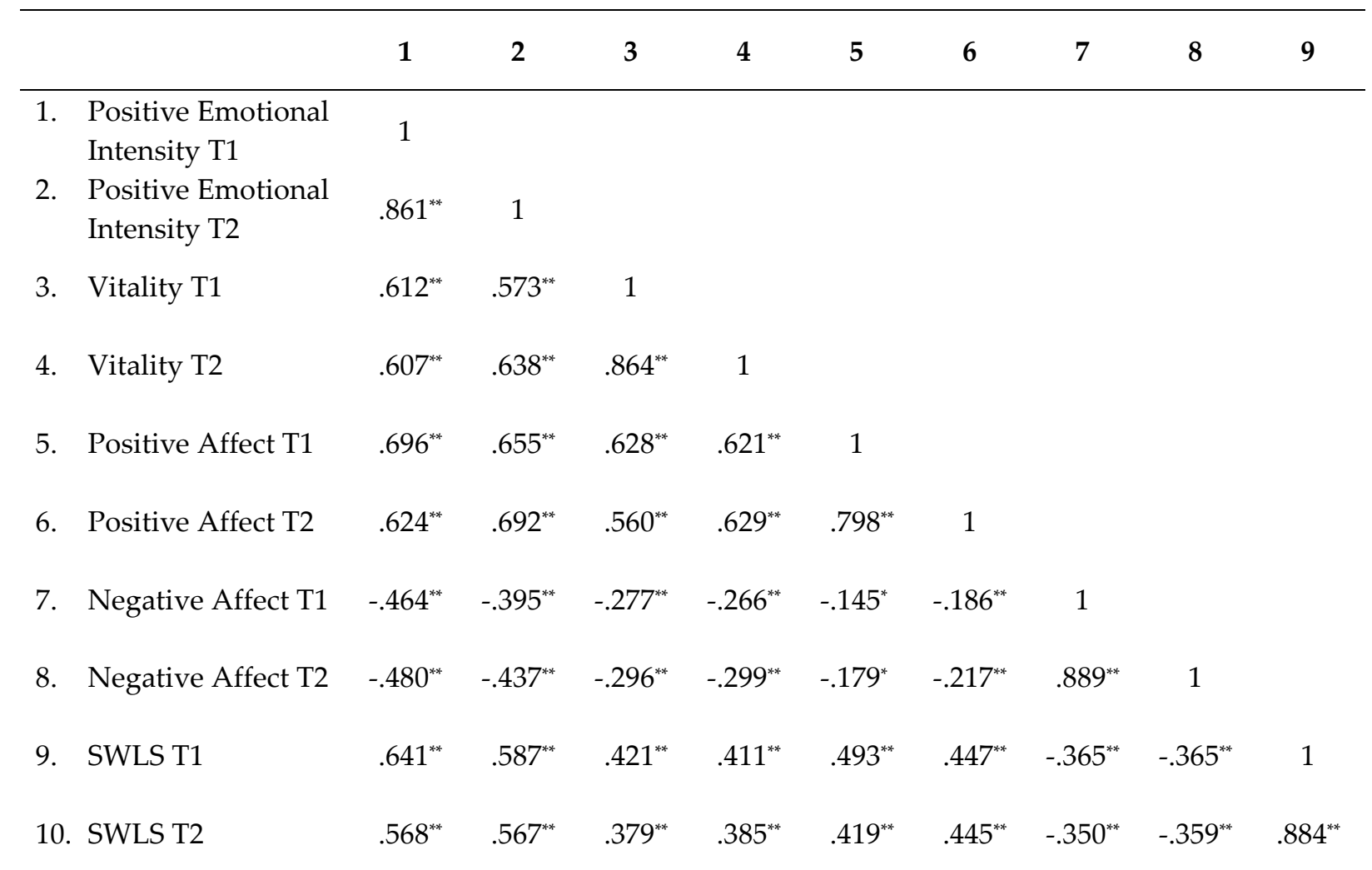

Note: ${ }^{*}$ Correlation is significant at the $p<.05$ level. ${ }^{* *}$ Correlation is significant at the $p<.01$ level. T1 $=$ Time 1. T2 $=$ Time 2.

\section{Results}

\subsection{Differences in Time 1 study measures}

The Time 1 Positive Emotional Intensity, Positive Affect, Negative Affect, Satisfaction with Life and Vitality data were analyzed using a MANOVA with intervention group as a Fixed Factor and the Time 1 study measures as Dependent Variables. Using the Wilks Lambda statistic, there were no significant differences between the intervention groups $(F(15,530)=0.92 ; p=.54$, partial $\left.\eta^{2}=.023\right)$ across the Time 1 study measures.

\subsection{Impact of eating and gifting on Positive Emotional Intensity}

The Time 2 Positive Emotional Intensity data were analyzed using a two-way ANCOVA with eating (eating / no eating) and gifting (gift / no gift) as Between Subjects Factors and the Time 1 Positive Emotional Intensity data as a Covariate.

A significant main effect of eating was observed $\left(F(1,195)=7.28, p<.01, \eta^{2}=.036\right)$. The estimated marginal means for eating are displayed in Table 2 below. The means indicate that Positive Emotional Intensity is higher for eating conditions compared to non-eating conditions. Pairwise comparisons, using the Bonferroni correction, confirmed this difference was significant $(p<.01)$.

The main effect of gifting was not significant $\left(F(1,195)=0.22, p=.64, \eta^{2}=.001\right)$ indicating that giving an ice cream did not impact Positive Emotional Intensity. The interaction between eating and gifting was also non-significant $\left(F(1,195)=0.002, p=.96, \eta^{2}=.000\right)$. 
Table 2: Estimated marginal means for significant main effects

\begin{tabular}{llc}
\hline Study Measure & Condition & Estimated Marginal Mean \\
\hline Positive Emotional Intensity & Eating & 53.44 \\
& No eating & 51.85 \\
Resilient Intensity & & \\
& Eating & 3.16 \\
& No eating & 2.91 \\
Grateful Intensity & Eating & 4.09 \\
& No eating & 3.67 \\
Gifting & 4.00 \\
Content Intensity & No gifting & 3.76 \\
& & \\
Positive Affect & Eating & 4.04 \\
& No eating & 3.80 \\
& & \\
& Eating & 32.69 \\
& No eating & 31.01 \\
& Gifting & 32.47 \\
\hline
\end{tabular}

In order to explore these results further, we were interested in whether the increase in overall Positive Emotional Intensity in the eating conditions was driven by any specific positive emotions in particular.

To explore this, the 15 Time 2 Positive Emotional Intensity items were analyzed using a 2way MANCOVA, in order to control for multiple tests, with eating (eating / no eating) and gifting (gift / no gift) as Between Subjects Factors and the 15 Time 1 Positive Emotional Intensity items as Covariates.

Using the Wilks Lambda statistic, there was a significant effect of eating on the Positive Emotional Intensity items $\left(F(15,167)=2.44 ; p<.01\right.$, partial $\left.\eta^{2}=.180\right)$. Follow up one-way ANOVAs indicated significant effects for the positive emotional intensity of feeling Grateful $(F$ $(1,181)=16.89 ; p<.001$, partial $\left.\eta^{2}=.085\right)$, Resilient $\left(F(1,181)=5.48 ; p<.05\right.$, partial $\left.\eta^{2}=.029\right)$ and Content $\left(F(1,181)=7.54 ; p<.01\right.$, partial $\left.\eta^{2}=.040\right)$. The estimated marginal means for eating across the emotions of Grateful, Resilient and Content are displayed in Table 2 above. The means indicate that the positive emotional intensity of feeling Grateful, Resilient and Content is higher for eating conditions compared to non-eating conditions. Pairwise comparisons, using the Bonferroni correction, confirmed this difference was significant for Grateful $(p<.001)$, Content $(p<.01)$ and Resilient $(p<.05)$.

Using the Wilks Lambda statistic, there was no significant effect of gifting on the Positive Emotional Intensity items $\left(F(15,167)=1.36 ; p=.172\right.$, partial $\left.\eta^{2}=.109\right)$.

Using the Wilks Lambda statistic, there was no significant interaction between eating and gifting for the Positive Emotional Intensity items $\left(F(15,167)=1.44 ; p=.134\right.$, partial $\left.\eta^{2}=.115\right)$.

\subsection{Impact of eating and gifting on Positive Affect}

The Time 2 Positive Affect data were analyzed using a two-way ANCOVA with eating (eating / no eating) and gifting (gift / no gift) as Between Subjects Factors and the Time 1 Positive Affect data as a Covariate. 
A significant main effect of eating was observed $\left(F(1,195)=8.51, p<.01\right.$, partial $\left.\eta^{2}=.042\right)$. The estimated marginal means for eating are displayed in Table 2 above. The means indicate that Positive Affect is higher for eating conditions compared to non-eating conditions. Pairwise comparisons, using the Bonferroni correction, confirmed this difference was significant $(p<.01)$.

A significant main effect of gifting was observed $\left(F(1,195)=4.57, p<.05\right.$, partial $\left.\eta^{2}=.023\right)$. The estimated marginal means for gifting are displayed in Table 2 above. The means indicate that Positive Affect is higher for gifting conditions compared to non-gifting conditions. Pairwise comparisons, using the Bonferroni correction, confirmed this difference was significant $(p<.05)$.

The interaction between gifting and eating was also significant $(F(1,195)=9.84, p<.01$, partial $\left.\eta^{2}=.048\right)$. The estimated marginal means for the interaction are displayed in Table 3 below, where it is shown that eating and gifting, both alone and together, have a positive impact on levels of Positive Affect.

Table 3: Estimated marginal means for significant interaction effects

\begin{tabular}{lllc}
\hline Study Measure & Eating & Gifting & Estimated Marginal Mean \\
\hline Positive Affect & Eating & Gifting & 32.40 \\
& & No gifting & 32.99 \\
& No eating & Gifting & 32.53 \\
& & No gifting & 29.48 \\
\hline
\end{tabular}

This interaction effect is shown graphically in Figure 1 below. This interaction effect suggests that if you give an ice cream, Positive Affect is stable regardless of whether you eat ice cream or not. However, if you don't give an ice cream, it is only eating ice cream that achieves a higher level of Positive Affect, relative to the control group.

Figure 1: Interaction effect for eating and gifting on positive affect

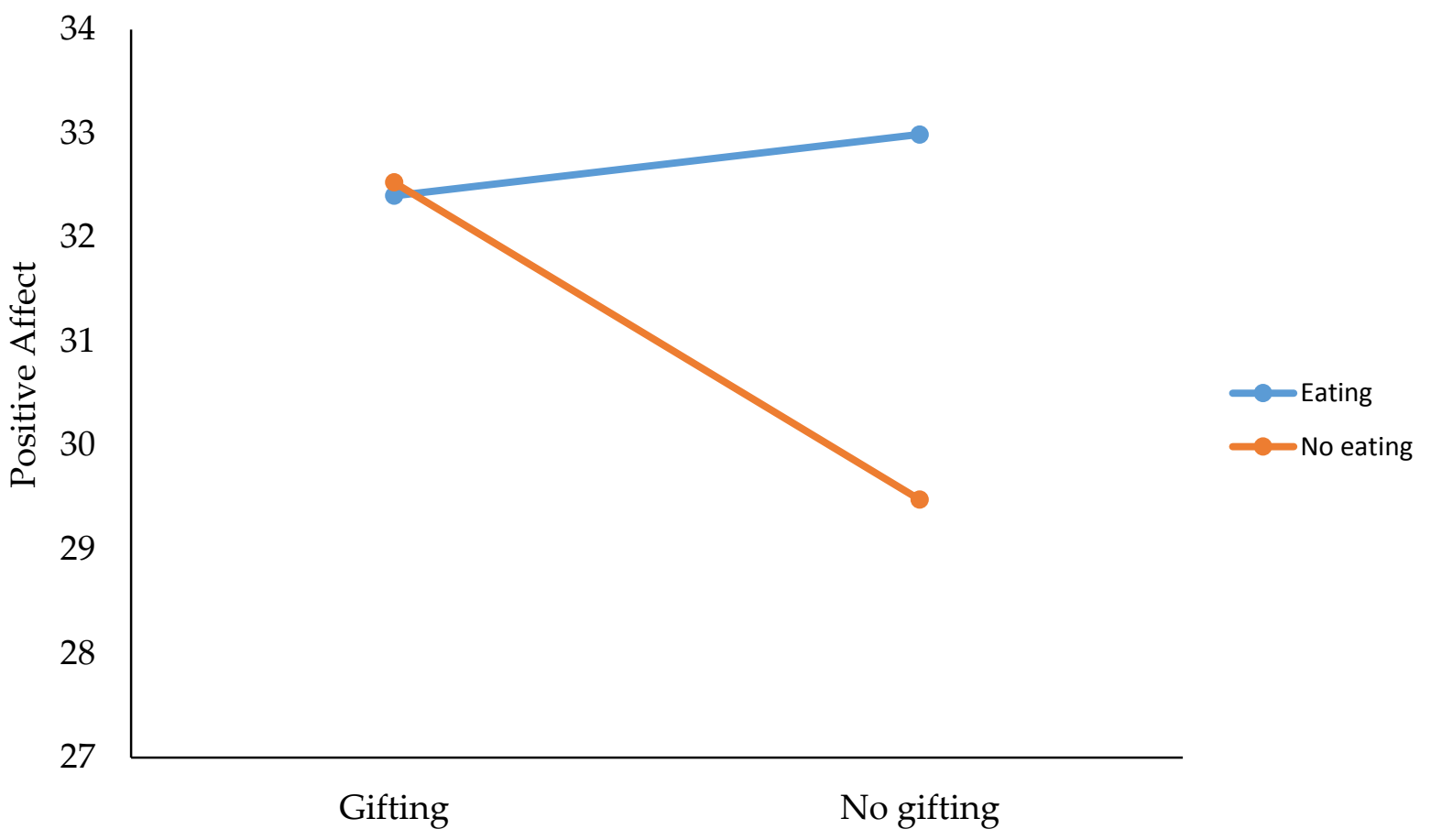




\subsection{Impact of eating and gifting on Negative Affect, Satisfaction with Life and Vitality}

All main effects and interactions were non-significant for each of Negative Affect, Satisfaction with Life and Vitality.

\section{Discussion}

This study aimed to explore the effect of eating or gifting an ice cream on general Positive Affect, discrete positive emotions and wellbeing. The study used a number of measures to do this, which reveal interesting results. First, gifting an ice cream to another person was found to increase Positive Affect only. This finding lends partial support for hypothesis 1; that giving an ice cream as a gift is effective in increasing general Positive Affect and discrete positive emotions and also converges with previous research in the gifting behaviour literature (e.g. Steger, Kashdan, \& Oishi, 2008). It is interesting to note that the time 1 positive emotional intensity levels for the gifting group was equivalent to the time 2 positive emotional intensity level achieved by the other two experimental conditions. Given the random allocation to groups, this is a statistical anomaly, but may provide one reason why we did not see a significant effect of giving an ice cream on positive emotional intensity: because participants in this group were already experiencing the same level of positive emotional intensity that other experimental participants reached following their intervention.

Second, eating an ice cream was found to increase positive emotional intensity and Positive Affect. These findings lend support for hypothesis 2 that eating ice cream alone is effective in increasing general Positive Affect and discrete positive emotions and are in line with previous research findings (e.g., Isen \& Levin, 1972; Linley et al., 2013). It is notable that there was a difference in Positive Affect scores of 3.5 points (equivalent to a Positive Affect score greater by $11.9 \%$ ) between people who consumed an ice cream and people who neither consumed an ice cream nor gifted an ice cream to someone else. Given that this was a simple everyday event, which occurred within a short timeframe (e.g., 10-15 minutes), this difference in levels of Positive Affect could be considered clinically significant. In practical terms, this may suggest that there was a real-life impact on participants from their eating of the ice cream, and the reported increases in Positive Affect that followed. Of course, we do not know whether this was simply a Positive Affect spike, or whether this increase will have been in any way maintained, a topic to which we return below.

Third, eating ice cream and giving an ice cream together were also found to increase positive emotional intensity and Positive Affect. This offers partial support for hypothesis 3 that the simultaneous act of eating and gifting would lead to a "double benefit" in increasing general Positive Affect and discrete positive emotions. However, we did not find evidence for any additive or cumulative effect: that this double activity would lead to double benefit and so higher wellbeing scores than either giving an ice cream or eating ice cream alone.

Taken together, these results suggest that the activities of eating ice cream and giving an ice cream, both independently and together, are effective everyday behavioural strategies for at least temporarily increasing the level of positive emotion people experience. This adds to the literature on developing and testing specific interventions for increasing happiness by including alternative strategies less explored by previous research, namely eating and gifting. Notably, these activities are much more everyday activities than have typically been reported in the positive psychology literature to date, suggesting that there may be different everyday activities that provide routes to happiness that have yet to be sufficiently explored.

Given the emerging focus on discrete positive emotions (e.g., Lench et al., 2011), rather than broader omnibus measures of positive emotion, we also examined the question of whether 
specific, discrete positive emotions were driving the overall significance of the positive emotion effects of eating. Analyses of the discrete positive emotions revealed that the positive emotional intensity of feeling grateful, content and resilient were all significantly higher in the eating conditions.

From this evidence, it is possible that interventions that continually raise people's awareness of the positive emotions associated with everyday activities might lead to longer-term increases in wellbeing. Note that we are not suggesting people should focus on one particular type of naturalistic activity, such as eating ice cream, but instead that this evidence encourages us to consider the multiple sources of Positive Affect already generated in our everyday life from a wide range of behaviours. Further research examining the duration of the positive changes to momentary positive emotional intensity and Positive Affect would provide greater clarity on this possibility. It is also understood that longer-term happiness is built up over time from repeated frequency of Positive Affective experiences (Diener, Sandvik, \& Pavot, 1991), of which gifting and eating ice cream are examples. As such, while these activities lead only to momentary impact, they may also, when repeated over time, lead to longer-term increases in sustainable happiness. Indeed, there are many other sources of everyday positive emotions to accumulate positive experiences over time, including, for example, admiring the beauty of nature, appreciating small acts of kindness, and enjoying the warm glow of friendship. All of these everyday activities lend themselves as candidates for future research into more everyday general Positive Affect and discrete positive emotions and their accumulative impact on happiness.

There are also other potential interpretations of these findings which cannot be ruled out from the current evidence, and so lend themselves to future research directions. First, it is possible that the active mechanism that led to positive emotion increases from eating an ice cream was not the actual act of eating the ice cream, but rather the experience of receiving the gift of an ice cream (the same alternative interpretation that we noted above could be applied to Isen and Levin's (1972) study).

Second, the gifting conditions could also be confounded with social contact, in that the experience of being with another person as they ate their ice cream could have impacted on the positive emotions of the participant, rather than purely the act of giving the gift of the ice cream itself. This seems plausible given the mechanisms for how acts of kindness can increase positive emotions that were discussed by Lyubomirsky et al. (2005).

Third, each of the eating and gifting conditions involved having access to resources (i.e., an ice cream) that the participants did not have to acquire themselves. As such, the act of 'spending someone else's money' could have been the active mechanism.

Fourth, whilst we found an increase in resilience, monitored as a short-term emotional experience, this may have been a projection of the participants' boost in positive feeling, rather than the basis for longer term resilient self-reflection as proposed by the Broaden and Build Model. Further research is needed over several weeks, using cognitive measures of resilience, to confirm this as a beneficial effect.

Fifth, clearly our results are based on responses from the UK participants recruited for this study and may not be representative of other populations.

Sixth, desirable foods contain nutrients that are likely to have a direct physiological and perhaps also indirect psychological impact (Drewnowski, 1997; Leigh Gibson, \& Green, 2002; Van Oudenhove et al., 2011). Whilst this nutrient-based physiological mechanism was clearly not contributing to the impact of gifting it may have played a role during the eating condition.

All of these considerations lend themselves to interesting directions for future research. Nonetheless, these findings suggest an extension to existing knowledge by highlighting the role 
of more everyday activities and the role these activities may play in promoting happiness. Typical positive psychology studies to date have not focused on natural, everyday behaviours, but instead are established by researchers as changes in people's daily behaviour (e.g., random acts of kindness, writing a gratitude letter, recording a gratitude diary, visualising your best possible self).

In contrast, the focus of the current study was on everyday activities, in this case, eating a desirable food (e.g. ice cream) and giving a desirable food to another person. This study indicated that these everyday activities had demonstrable effects on positive emotions and Positive Affect, perhaps indicating more natural, everyday mechanisms through which we may engage with promoting and building everyday happiness. As a result, the study opens up new avenues of exploration into the role that everyday activities and behaviours may have on momentary positive emotion and how these everyday activities can be re-framed as activities for the promotion of happiness over the longer term. For example, in addition to the eating and gifting of desirable foods, other everyday activities to explore include taking a break from work, the comfort and security provided by a building in bad weather, the creative act of preparing food, the sense of belonging from being part of a work group and the physical activity involved in a daily commute. This indicates an interesting and worthwhile new line of inquiry for positive psychology interventions research that focuses on the naturalistic activities that people may already be undertaking, on an everyday basis, to manage their own moods and increase their positive emotions.

\section{Authors}

Robert Hurling

Unilever

bob.hurling@unilever.com

Alex Linley

Centre for Applied Positive Psychology

Helen Dovey

Centre for Applied Positive Psychology

John Maltby

University of Leicester

Joy Wilkinson

Unilever

\section{Publishing Timeline}

Received 14 July 2014

Accepted 8 December 2014

Published 21 June 2015

\section{References}

Aknin, L. B., Barrington-Leigh, C. P., Dunn, E. W., Helliwell, J. F., Burns, J., Biswas-Diener, R., ... \& Norton, M. I. (2013). Prosocial spending and well-being: Cross-cultural evidence for a psychological universal. Journal of Personality and Social Psychology, 104(4), 635-652.

http://dx.doi.org/10.1037/a0031578 
Alden, L. E., \& Trew, J. L. (2013). If it makes you happy: Engaging in kind acts increases positive affect in socially anxious individuals. Emotion, 13, 64-75. http://dx.doi.org/10.1037/a0027761

Berenbaum, H. (2002). Varieties of joy-related pleasurable activities and feelings. Cognition and Emotion, 16(4), 473-494. http://dx.doi.org/10.1080/0269993014000383

Brickman, P., \& Campbell D. T. (1971). Hedonic relativism and planning the good society. In M. H. Appley (Ed.), Adaptation-level theory (pp. 287-302). New York: Academic Press.

Burger, K. S., \& Stice, E. (2012). Frequent ice cream consumption is associated with reduced striatal response to receipt of an ice cream-based milkshake. American Journal of Clinical Nutrition, 95, 810817. http://dx.doi.org/10.3945/ajcn.111.027003

Cheng, S. T. (2004). Endowment and contrast: The role of positive and negative emotions on well-being appraisal. Personality and Individual Differences, 37(5), 905-915. http://dx.doi.org/10.1016/j.paid.2003.10.013

Cohn, M. A., \& Fredrickson, B. F. (2010). In search of durable positive psychology interventions: Predictors and consequences of long-term behavioral change. Journal of Positive Psychology, 5, 355366. http://dx.doi.org/10.1080/17439760.2010.508883

Diener, E., Emmons, R. A., Larsen, R. J., \& Griffin, S. (1985). The satisfaction with life scale. Journal of Personality Assessment, 49, 71-75. http://dx.doi.org/10.1207/s15327752jpa4901 13

Diener, E., Lucas, R. E., \& Scollon, C. N. (2006). Beyond the hedonic treadmill: Revising the adaptation theory of well-being. American Psychologist, 61, 305-314. http://dx.doi.org/10.1037/0003-066X.61.4.305

Diener, E., Sandvik, E., \& Pavot, W. (1991). Happiness is the frequency, not the intensity, of positive versus negative affect. In F. Strack, M. Argyle, \& N. Schwarz (Eds.), Subjective well-being: An interdisciplinary perspective (pp. 119-139). New York: Pergamon.

Drewnowski, A. (1997). Taste preferences and food intake. Annual Review of Nutrition, 17(1), 237-253. http://dx.doi.org/10.1146/annurev.nutr.17.1.237

Dunn, E. W., Aknin, L. B., \& Norton, M. I. (2008). Spending money on others promotes happiness. Science, 319 (5870), 1687-1688. http://dx.doi.org/10.1126/science.1150952

Emmons, R. A., \& McCullough, M. E. (2003). Counting blessings versus burdens: An experimental investigation of gratitude and subjective well-being in daily life. Journal of Personality and Social Psychology, 84, 377-389. http://dx.doi.org/10.1037/0022-3514.84.2.377

Fredrickson, B. L., Cohn, M. A., Coffey, K. A., Pek, J., \& Finkel, S. M. (2008). Open hearts build lives: Positive emotions, induced through loving-kindness meditation, build consequential personal resources. Journal of Personality and Social Psychology, 95(5), 1045-1062. http://dx.doi.org/10.1037/a0013262

Fredrickson, B. L., \& Levenson, R. W. (1998). Positive emotions speed recovery from the cardiovascular sequelae of negative emotions. Cognition and Emotion, 12, 191-220. http://dx.doi.org/10.1080/026999398379718

Fredrickson, B. L., Tugade, M. M., Waugh, C. E., \& Larkin, G. R. (2003). What good are positive emotions in crises? A prospective study of resilience and emotions following the terrorist attacks on the United States on September 11th, 2001. Journal of Personality and Social Psychology, 84(2), 365-376. http://dx.doi.org/10.1037/0022-3514.84.2.365

Henderson, L. W., \& Knight, T. (2012). Integrating the hedonic and eudaimonic perspectives to more comprehensively understand wellbeing and pathways to wellbeing. International Journal of Wellbeing, 2(3), 196-221. http://dx.doi.org/10.5502/ijw.v2i3.3

Isen, A. M., \& Levin, P. F. (1972). The effect of feeling good on helping: Cookies and kindness. Journal of Personality and Social Psychology, 21, 384-388. http://dx.doi.org/10.1037/h0032317

Johnson, K. J., \& Fredrickson, B. L. (2005). "We all look the same to me:" Positive emotions eliminate the own-race bias in face recognition. Psychological Science, 16, 875-881. http://dx.doi.org/10.1111/j.14679280.2005.01631.x

Kahneman, D., Krueger A. B., Schkade D., Schwarz, N., \& Stone, A. A. (2004). A survey method for characterizing daily life experience: The day reconstruction method. Science, 306, 1776-1780. http://dx.doi.org/10.1126/science.1103572 
Kogan, A., Impett, E. A., Oveis, C., Hui, B., Gordon, A. M., \& Keltner, D. (2010). When giving feels good: The intrinsic benefits of sacrifice in romantic relationships for the communally motivated. Psychological Science, 21, 1918-1924. http://dx.doi.org/10.1177/0956797610388815

Kuppens, P., Tuerlinckx, F., Russell, J. A., \& Barrett, L. F. (2012). The relation between valence and arousal in subjective experience. Psychological Bulletin, 139(4), 917-940. http://dx.doi.org/10.1037/a0030811

Layous, K., Nelson, S. K., Oberle, E., Schonert-Reichl, K. A., \& Lyubomirsky, S. (2012). Kindness counts: Prompting prosocial behavior in preadolescents boosts peer acceptance and well-being. PLOS One, 7(12), e51380. http://dx.doi.org/10.1371/journal.pone.0051380

Leigh Gibson, E., \& Green, M. W. (2002). Nutritional influences on cognitive function: Mechanisms of susceptibility. Nutrition Research Reviews, 15(1), 169-206. http://dx.doi.org/10.1079/NRR200131

Lench, H. C., Flores, S. A., \& Bench, S. W. (2011). Discrete emotions predict changes in cognition, judgment, experience, behavior, and physiology: A meta-analysis of experimental emotion elicitations. Psychological Bulletin, 137, 834-855. http://dx.doi.org/10.1037/a0024244

Linley, P. A., Dovey, H., de Bruin, E., Transler, C., Wilkinson, J., Maltby, J., \& Hurling, R. (2013). Two simple, brief, naturalistic activities and their impact on positive affect: Feeling grateful and eating ice cream. Psychology of Well-Being: Theory, Research and Practice. 3(6), 1-14. http://dx.doi.org/10.1186/2211-1522-3-6

Linley, P. A., Maltby, J., Wood, A. M., Osborne, G., \& Hurling, R. (2009). Measuring happiness: The higher order factor structure of subjective and psychological well-being measures. Personality and Individual Differences, 47(8), 878-884. http://dx.doi.org/10.1016/j.paid.2009.07.010

Lyubomirsky, S. \& Layous, K. (2013). The how, who, what, when, and why of happiness: Mechanisms underlying the success of positive interventions. To appear in J. Gruber \& J. Moscowitz (Eds.), The light and dark side of positive emotions. New York: Oxford University Press.

Lyubomirsky, S., King, L., \& Diener, E. (2005). The benefits of frequent positive affect: Does happiness lead to success? Psychological Bulletin, 131, 803-855. http://dx.doi.org/10.1037/0033-2909.131.6.803

Lyubomirsky, S., \& Lepper, H. S. (1999). A measure of subjective happiness: Preliminary reliability and construct validation. Social Indicators Research, 46, 137-155. http://dx.doi.org/10.1023/A:1006824100041

Lyubomirsky, S., Sheldon, K. M., \& Schkade, D. (2005). Pursuing happiness: The architecture of sustainable change. Review of General Psychology, 9, 111-131. http://dx.doi.org/10.1037/10892680.9.2.111

Macht, M., Meininger, J., \& Roth, J. (2005). The pleasures of eating: A qualitative analysis. Journal of Happiness Studies, 6, 137-160. http://dx.doi.org/10.1007/s10902-005-0287-x

McMahan, E. A., \& Estes, D. (2011). Measuring lay conceptions of well-being: The beliefs about wellbeing scale. Journal of Happiness Studies, 12, 267-287. http://dx.doi.org/10.1007/s10902-010-9194-x

Michie, S. (2009). Pride and gratitude: How positive emotions influence the prosocial behaviors of organizational leaders. Journal of Leadership and Organizational Studies, 15, 393-403. http://dx.doi.org/10.1177/1548051809333338

Parks, A. C., Della Porta, M. D., Pierce, R. S., Zilca, R., \& Lyubomirsky, S. (2012). Pursuing happiness in everyday life: The characteristics and behaviors of online happiness seekers. Emotion, 12(6), 12221234. http://dx.doi.org/10.1037/a0028587

Pavot, W., \& Diener, E. (1993). Review of the satisfaction with life scale. Psychological Assessment, 5(2), 164-172. http://dx.doi.org/10.1037/1040-3590.5.2.164

Post, S. G. (2005). Altruism, happiness, and health: It's good to be good. International Journal of Behavioral Medicine, 12(5), 66-77. http://dx.doi.org/10.1207/s15327558ijbm1202 4

Pressman, S. D., \& Cohen, S. (2005). Does positive affect influence health? Psychological Bulletin, 131, 925971. http://dx.doi.org/10.1037/0033-2909.131.6.925

Rozin, P. (1999). Preadaptation and the puzzles and properties of pleasure. In D. Kahneman, E. Diener, \& N. Schwarz (Eds.), Well-being: The foundations of hedonic psychology. (pp.109-132). New York: Russell Sage Foundation. 
Rozin, P., Fischler, C., Imada, S., Sarubin, A., \& Wrzesniewski, A. (1999). Attitudes to food and the role of food in life in the USA, Japan, Flemish Belgium and France: Possible implications for the diet-health debate. Appetite, 33, 163-180. http://dx.doi.org/10.1006/appe.1999.0244

Ryan, R. M., \& Frederick, C. M. (1997). On energy, personality and health: Subjective vitality as a dynamic reflection of well-being. Journal of Personality, 65, 529-565. http://dx.doi.org/10.1111/j.14676494.1997.tb00326.x

Seligman, M. E. P., \& Csikszentmihalyi, M. (2000). Positive psychology: An introduction. American Psychologist, 55, 5-14. http://dx.doi.org/10.1037/0003-066X.55.1.5

Sheldon, K. M. \& Elliot, A. J. (1999). Goal striving, need satisfaction, and longitudinal well-being: The Self-Concordance Model. Journal of Personality and Social Psychology, 76, 482-497. http://dx.doi.org/10.1037/0022-3514.76.3.482

Sheldon, K. M., \& Lyubomirsky, S. (2006). Achieving sustainable gains in happiness: Change your actions, not your circumstances. Journal of Happiness Studies, 7, 55-86. http://dx.doi.org/10.1007/s10902-005-0868-8

Sin, N. L., \& Lyubomirsky, S. (2009). Enhancing well-being and alleviating depressive symptoms with positive psychology interventions: A practice-friendly meta-analysis. Journal of Clinical Psychology: In Session, 65, 467-487. http://dx.doi.org/10.1002/jclp.20593

Steger, F. M, Kashdan, T. B., \& Oishi, S. (2008). Being good by doing good: Daily eudaimonic activity and well-being. Journal of Research in Personality, 42, 22-42. http://dx.doi.org/10.1016/j.jrp.2007.03.004

Strohminger, N., Lewis, R. L., \& Meyer, D. E. (2011). Divergent effects of different positive emotions on moral judgment. Cognition, 119, 295-300. http://dx.doi.org/10.1016/j.cognition.2010.12.012

Van Oudenhove, L., McKie, S., Lassman, D., Uddin, B., Paine, P., Coen, S., ... \& Aziz, Q. (2011). Fatty acid-induced gut-brain signaling attenuates neural and behavioral effects of sad emotion in humans. The Journal of Clinical Investigation, 121(8), 3094-3099. http://dx.doi.org/10.1172/JCI46380

Veldhuizen, M. G., Rudenga, K. J., \& Small, D. M. (2010). The pleasure of taste, flavor and food. In M. L. Kringelbach \& K. C. Berridge (Eds.), Pleasures of the brain (pp. 146-168). New York: Oxford University Press.

Walla, P., Richter, M., Farber, S., Leodolter, U., \& Bauer, H. (2010). Food-evoked changes in humans' startle response modulation and event-related brain potentials (ERPs). Journal of Psychophysiology, 24, 25-32.

Watkins, P. C., Woodward, K., Stone, T., \& Kolts, R. L. (2003). Gratitude and happiness: Development of a measure of gratitude, and relationships with subjective well-being. Social Behavior and Personality, 31, 431-451. http://dx.doi.org/10.2224/sbp.2003.31.5.431

Watson, D., Clark, L. A., \& Tellegen, A. (1988). Development and validation of brief measures of positive and negative affect: The PANAS scales. Journal of Personality and Social Psychology, 54, 1063-1070. http://dx.doi.org/10.1037/0022-3514.54.6.1063

Waugh, C. E., \& Fredrickson, B. L. (2006). Nice to know you: Positive emotions, self-other overlap, and complex understanding in the formation of new relationships. Journal of Positive Psychology, 1, 93106. http://dx.doi.org/10.1080/17439760500510569

Weinstein, N., \& Ryan, R. M. (2010). When helping helps: Autonomous motivation for prosocial behavior and its influence on well-being for the helper and recipient. Journal of Personality and Social Psychology, 98, 222-244. http://dx.doi.org/10.1037/a0016984

Williams, L. A., \& DeSteno, D. (2008). Pride and perseverance: The motivational role of pride. Journal of Personality and Social Psychology, 94, 1007-1017. http://dx.doi.org/10.1037/0022-3514.94.6.1007

Wilson, T. D., \& Gilbert, D. T. (2005). Affective forecasting: Knowing what to want. Current Directions in Psychological Science, 14 (3), 131-134. http://dx.doi.org/10.1111/j.0963-7214.2005.00355.x

Wrzesniewski, A., Rozin, P., \& Bennett, G. (2003). Working, playing, and eating: Making the most of most moments. In C. L. M. Keyes \& J. Haidt (Eds.), Flourishing: Positive psychology and the life well-lived (pp.185-204). Washington, D.C.: American Psychological Association.

http://dx.doi.org/10.1037/10594-008 